\title{
Notícias do maio de 1968 parisiense nas páginas do jornal gaúcho Correio do Povo*
}

Cyanna Missaglia de Fochesatto ${ }^{1}$

Resumo: O ano de 1968 foi marcante para a sociedade brasileira, bem como para o mundo de forma geral. Assim, torna-se relevante abordar os temas relacionados às manifestações estudantis e operárias ocorridas nesse período. Os anos 60 se caracterizam pela intensa onda de reivindicações e protestos que começam a ocorrer em quase todas as partes do mundo, visando uma estrutura sócio-política mais moderna e democrática. Além disso, é um período rico em manifestações culturais e artísticas que, em conjunto, legam à sociedade novos modos de vida, de relações e de mentalidade. É intenção desse trabalho investigar as notícias referentes ao mês de maio de 1968 nas páginas do jornal gaúcho Correio do Povo, um dos periódicos de maior importância para o Estado do Rio Grande do Sul desse período, analisando, assim, como foram veiculadas as notícias referentes a este tema.

Palavras-chave: Maio de 1968; Correio do Povo; Movimento Estudantil.

Abstract: The year 1968 was striking for Brazilian society and for the world in general. Thus, it becomes important to address issues related to student demonstrations and workers during that period. The 60's are characterized by intense wave of protests and claims that begin to occur in almost all parts of the world, seeking a socio-political structure modern and democratic. Besides, it is a period rich in cultural and artistic events that together bequeath to society new ways of life, relationships and mindset. It is the intention of this work to investigate the news for the month of May 1968 in the pages of the newspaper Correio do Povo, one of the journals of greatest importance to the State of Rio Grande do Sul during that period, analyzing as well related news published on this topic.

Keywords: May 1968; Correio do Povo; Student Movement.

\section{Introdução}

O presente trabalho propõe-se a analisar o mês de maio de 1968 nas páginas do jornal Correio do Povo. Essa data foi escolhida devido à grande importância desse ano para a história do mundo e às transformações decorridas em diversos locais a partir desse momento, como por exemplo, a decadência de alguns valores religiosos e familiares; maior liberdade

\footnotetext{
* Artigo submetido em 22 de outubro de 2012 e aceito para publicação em 10 de janeiro 2013.

${ }^{1}$ Bacharel em História pela PUCRS. Especialista em Estudos Culturais nos currículos escolares pela UFRGS, e Mestranda do PPGH da UNISINOS. Bolsista CAPES/Prosup. E-mail: cyanna.mf@gmail.com.
}

Em Tempo de Histórias

Publicação do Programa de Pós-Graduação em História da Universidade de Brasília (PPGHIS/UnB)

$\mathrm{N}^{\circ} .23$, Brasília, ago. - dez. 2013

ISSN 2316-1191 
sexual; movimentos feministas; surgimento de uma cultura diferenciada; enfim, um novo tipo de comportamento na sociedade. Assim, busca-se no texto a seguir compreender como as notícias do maio de 1968 de Paris foram veiculadas na sociedade gaúcha, fazendo, quando possível, referências às notícias de acontecimentos ocorridos no próprio Brasil. Também se tem por objetivo entender de que forma a imprensa noticiou as matérias referentes às reivindicações em um período de ditadura e censura no Brasil. Este estudo vale-se, ainda, da análise da bibliografia específica sobre o assunto. Entre os autores recorridos citam-se Eric Hobsbawn, Tony Judt, Heloisa B. de Hollanda e Zuenir Ventura.

Para compreender as ondas de reivindicações que ocorrem em quase todo o globo nesse ano, é necessário, primeiramente, entender o contexto em que essas movimentações realizaram-se. A relevância cultural, social, política e econômica que os eventos relativos a esse ano tiveram na nossa sociedade são fundamentais para a compreensão da própria realidade em que estamos inseridos.

O curioso e talvez o mais interessante desse período seja que as manifestações ocorreram partindo da classe estudantil que, em sua maioria, fazia parte da chamada classe média. Contudo, a onda reivindicatória vinda desses estudantes atinge os setores trabalhistas da sociedade, formando, assim, uma grande massa de trabalhadores e estudantes exigindo o que de fato tinham por direito, e o que o próprio contexto lhes exigia: modernidade, liberdade, democracia, melhores condições de vida, de salário e de trabalho, crítica à sociedade de consumo, às burocracias, aos regimes autoritários e retrógrados, à rigidez das instituições educacionais, aos valores conservadores, aos hábitos e costumes vigentes.

Assim, é fundamental, mesmo que de forma breve, abordar o tipo de veículo de comunicação que será trabalhado nessa pesquisa, contextualizado e analisado em seu conteúdo. O jornal Correio do Povo $^{2}$ foi escolhido devido à sua grande importância nesse período dos anos 60. Esse jornal foi um dos mais influentes e de maior circulação no Rio

\footnotetext{
2 O jornal Correio do Povo, fundado em 1895 por Francisco Antônio Vieira Caldas Júnior, acabou crescendo rapidamente e conquistando o mercado. Caracteriza-se, inicialmente, como inovador no sentido de ser o primeiro jornal a organizar-se como empresa com finalidades lucrativas, possibilitando a construção de um novo regime jornalístico.
} 
Grande do Sul, em um momento de ditadura e repressão. Sob direção de Breno Caldas ${ }^{3}$, filho do fundador, podemos afirmar que a posição do Correio e do próprio Breno, homem conservador, foi de apoiar, abertamente, o golpe militar de 1964. No entanto, estabeleceu uma relação de apoio à ditadura e ao mesmo tempo de apoio à liberdade de imprensa, tendo, inclusive, uma de suas edições inteiramente censurada e recolhida, justamente por defender essa causa em suas páginas (GALVANI, 1999). Essa postura do jornal gaúcho não foi novidade, uma vez que "a maioria dos grandes jornais do país apoiou, ao menos no início, o golpe militar de 1964.” (MARTINS; LUCA, 2008: 182).

Sobre os meios de comunicação de um modo geral, o autor Daniel Aarão Reis (2000), afirma que, em especial a televisão, teve um relevante papel no ano de 1968, devido ao seu caráter global: as imagens televisionadas mostravam a guerra no Vietnã, as barricadas francesas, as repercussões desses movimentos, a cultura, a música, as novas modas, os protestos. $\mathrm{O}$ que esteve relacionado às transformações dos anos 60 chegava por esse meio até a população brasileira. Em contraponto a essa inovação que os meios de comunicação, como a televisão, propiciaram, no Brasil, a censura vivida durante o período da ditadura mascarou os acontecimentos e tinha como papel impedir que informações negativas sobre o regime chegassem ao conhecimento geral do público:

No chamado período pós-1964, o Correio do Povo, assim como os demais órgãos jornalísticos do país, estava sujeito a censura federal. As matérias eram lidas pelos censores, que, caso considerassem algum conteúdo impublicável, deixavam-no de fora ou, simplesmente, jogavam a matéria no lixo. (DILLENBURG, 1997: 76).

Assim, cabe contextualizar esse período de repressões e censuras, de forma a reafirmar que o contexto é muito importante para a compreensão dos acontecimentos que se seguem no ano de 1968.

\section{Contexto histórico dos anos 60}

\footnotetext{
3 Antônio Vieira Caldas Júnior, acabou crescendo rapidamente e conquistando o mercado. Caracteriza-se, inicialmente, como inovador no sentido de ser o primeiro jornal a organizar-se como empresa com finalidades lucrativas, possibilitando a construção de um novo regime jornalístico.
} 
O período dos anos 60, como já foi mencionado, é rico em acontecimentos nos níveis sociais, culturais e políticos. As mudanças que decorrem desse período transformam não só a estrutura da sociedade, mas também as relações interpessoais dos diversos grupos. Outra peculiaridade que temos na década de 60 e nos acontecimentos do ano de 68 é que não se limitam às esferas particulares de cada país: 1968 cobre parte do globo com manifestações e protestos; é a população que está envolvida nas manifestações, disseminando sua urgência por transformações e mudanças.

Um contexto dessa situação proveniente dos anos 60 é o da Guerra Fria, quando o mundo encontra-se bipolarizado, vivendo sob o medo da guerra nuclear e de uma nova era de catástrofes, tendo anteriormente já vivenciado isso com a $2^{\mathrm{a}}$ Guerra Mundial. A divisão do mundo ficava então marcada entre o ideal de vida norte americano e o comunismo soviético, que deveria ser arduamente combatido -principalmente pelos norte americanos-, a fim de assegurar uma sociedade liberal, capitalista e "democrática" (HOBSBAWN, 1997: 223-253). É importante salientar que esse contexto também propicia a instalação dos regimes ditatoriais na América Latina, como foi o caso do Brasil. Forma-se então, um paradoxo que não podemos deixar de citar. Os anos 60, por um lado, marcaram a luta pela liberdade e os movimentos contestatórios em prol da democracia; por outro, marcam a ascensão de regimes autoritários na América Latina.

Na França, a movimentação do ano de 1968 ocorre inicialmente em um protesto estudantil que renega a instituição educacional do país, considerada pelos estudantes como retrógrada, antiquada, inapropriada para os moldes da sociedade moderna, com aspectos ainda "medievais", conservadora e burocrática. Logo, as manifestações se espalham pelas fábricas abarcando funcionários, operários e trabalhadores que reivindicavam melhores salários, condições de vida e de trabalho. O General De Gaulle, fundador do partido Republicano Francês e da Quinta República Francesa (1958), estava no poder governando por um sistema considerado, pelos estudantes, conservador, autoritário e centralizador. Propôs que o Presidente da República fosse eleito por voto universal e acabou tendo mais poder do que qualquer outro chefe de estado do mundo, escolhido por meio de eleições livres. Elaborou 
uma radical reforma econômica no país, definindo a variação de um novo franco e a estabilização das finanças francesas. O Presidente mantinha viva a memória das humilhações sofridas anteriormente no período da guerra e tinha, portanto, como ideal, resgatar a grandeza da França de antigamente (JUDT, 2008: 298).

A França foi passando por transformações político-econômicas, mas que em alguns setores não acompanhavam o desenvolvimento e a modernidade, principalmente emergidos nos anos 60. Em 1968, o país transformou-se em um grande cenário de manifestações. Segundo Heloisa B. de Hollanda (1982: 69): “A França, centro de agitação estudantil, presenciava a eclosão do já mitológico Maio de 68, quando as ruas de Paris viram-se transformadas em cenário de uma verdadeira Guerra Civil”.

No entanto, conforme já mencionado, essa década de forte movimentação e protestos, não se limita à França e ao Brasil, mas se pode afirmar que boa parte do mundo entrou nessa onda reivindicatória. Nos Estados Unidos da América os acontecimentos são intensos: parte da população se posiciona fortemente contra a Guerra do Vietnã; em 1968 morre o líder negro Marthin Luther King, grande expoente do Movimento Negro; ocorre forte contestação cultural com o surgimento de diversos movimentos sociais. A adesão de outros países nesse momento expandiu essa leva de movimentos contestatórios. 1968 é um importante ano, por exemplo, para a Tchecolosváquia, que após uma fracassada tentativa de democratização e abertura do país, feita por Alexander Dubcek, é invadida pelas tropas do Pacto de Varsóvia episódio conhecido como a Primavera de Praga. Outros países da Europa também participam dessa onda de protestos e movimentos sociais e culturais, como por exemplo, a Itália e a Alemanha. (SCHILLING, 2008: 1-32).

Para o México, esse ano fica registrado como o ano das Olimpíadas, quando, já se sabendo que o mundo voltava seus olhos para o país, estudantes e trabalhadores se organizaram em diferentes tipos de passeatas e protestos contra o regime político do PRI (Partido Revolucionario Institucional), de Díaz Ordaz. O auge desse período para o México foi o massacre de Tlatelolco, em 1968, onde a polícia atacou a tiros os manifestantes. O número de mortes é impreciso, porém alarmante (TRONCOSO, 2008: 11-34). 
Dessa forma, sobre o contexto de 68, a autora Heloisa B. de Hollanda (1982: 68-69) conclui:

Vivia-se o impacto de uma conjuntura marcada pelo acirramento de conflitos já não mais apenas nas sociedades periféricas -onde o enfrentamento do colonialismo e das ditaduras assumia feições dramáticas com a deflagração de processos de luta de guerrilha- como também nos países centrais que presenciavam o surgimento de uma intensa onda de protestos comandada pela juventude.

A cultura também ganha espaço nesse período: as movimentações de contracultura expressam, mudanças de estilo que distinguem os anos 60 , pelo questionamento da cultura oficial que era defendida e prezada pelo sistema, pode-se dizer, dominante. A propósito, pode ser citado o seguinte comentário sobre a contracultura: "Uma característica básica do fenômeno é o fato de se opor, de diferentes maneiras, à cultura vigente oficializada pelas principais instituições das sociedades do Ocidente.” (PEREIRA, 1985: 13).

No Brasil, conforme havíamos referido, em 1964, sob alegação de um ideário de democracia (REZENDE, 2001) e apoiado pelas classes patronais, anuncia-se o golpe militar colocando no poder o marechal Castelo Branco, que vai presidir o país até 1967. O Brasil passa por um processo de fechamento e endurecimento político; a militarização, o autoritarismo e a centralização do Estado passam a caracterizar o país desse período. É o início de um longo processo de repressão, torturas, perseguições, prisões e exílios ${ }^{4}$. Os direitos humanos e civis são desrespeitados em nome da força militar que pretende impedir qualquer tipo de subversão da “ordem”. Depois de Castelo Branco o poder passa ao também marechal Costa e Silva, que fica no governo até 1969. É em seu governo que se vivencia o furioso e reivindicador ano de 1968. Esse notoriamente mais rígido e "linha dura" (REZENDE, 2001: 89), também fica fortemente marcado pelo enrijecimento político, como expresso na emissão, em dezembro de 1968, do Ato Institucional $5 \multimap$ o AI-5 5 .

\footnotetext{
4 Esse primeiro momento da ditadura militar também ficou conhecido como "operação limpeza".

O AI-5 agrava o caráter antidemocrático da ditadura e seu endurecimento: "o quinto ato não previa prazo para deixar de vigorar; restabelecia e ampliava os poderes extraordinários do Presidente da República, já previstos no AI-1, onde ele poderia, por exemplo, decretar estado de sítio, sem consultar o Congresso; suspender direitos políticos, promover cassações, demitir, remover ou aposentar funcionários públicos; fechar o Congresso.
} 
Nesse momento, o país foi sacudido pela força da juventude, que mostrou seu poder e desgosto com o regime e com a sociedade, conforme registra o autor Zuenir Ventura (1988: 14):

Na verdade, a aventura dessa geração não é um folhetim de capa-e-espada, mas um romance sem ficção. $O$ melhor do seu legado não está no gestomuitas vezes desesperado; outras, autoritário- mas na paixão com que foi à luta, dando a impressão de que estava disposta a entregar a vida para não morrer de tédio. Poucas -certamente nenhuma depois dela-lutaram tão radicalmente pelo seu projeto, ou por sua utopia. Ela experimentou os limites de todos os horizontes: politicos, sexuais, comportamentais, existenciais, sonhando em aproximá-los todos.

Nesse contexto de luta pela liberdade e também de endurecimento da ditadura militar no Brasil, pretende-se analisar as notícias veiculadas no Rio Grande do Sul sobre o maio francês, tomando por referência o jornal Correio do Povo.

\section{Maio de 1968 no Correio do Povo}

Outro fator ganha espaço nesse conturbado mês, de protestos e greves, na França. A mídia volta seus olhos para a tão esperada Conferência de $\mathrm{Paz}^{6}$, noticiando amplamente o que estava acontecendo nesse referido episódio. Ambos os acontecimentos - ondas de protestos e a Conferência de Paz -vão tomar conta das páginas do jornal, e, se por um lado as manifestações colocam em risco a Conferência de Paz, por outro, talvez, os estudantes, aproveitando o momento favorável para repercussões na mídia, tenham se utilizado desse momento para intensificar as reivindicações.

O mês de maio de 1968 na França teve resultados significativos: "9 milhões de trabalhadores entram em greve. [...] Praticamente todos os setores da sociedade francesa se envolveram em certa medida." (SOLIDARITY, 2003: 104). Essa é a síntese do respaldo que as manifestações tiveram no que se refere à adesão e participação popular. Dessa forma, não é estranho que os meios de comunicação tenham dedicado atenção aos eventos do maio de

\footnotetext{
Além disso, o AI-5 previa a suspensão do habeas corpus para os crimes políticos, o que tornava praticamente impossível qualquer tipo de crítica aberta ao regime" (GERTZ, 2007: 95).

Paris foi sede de negociações de paz para o fim da Guerra do Vietnã. A Conferência de Paz tem início em maio de 1968.
} 
Paris. O jornal gaúcho Correio do Povo foi um desses veículos a ocupar-se da divulgação das imagens e matérias referentes a isso.

Assim, tanto quanto os protestos ocorridos, a Conferência de Paz (que acontecia paralelamente a isso na França), ganhou grande espaço nas páginas e capas do jornal. Notícias eram publicadas, tais como: "Paris convulsionada pelas agitações estudantis às vésperas da conferência"; "Madrugada de sangue e fogo na cidade escolhida para a conferência de paz"; "A capital da paz transformou-se em campo de guerra". Esse tipo de alusão era constante nas capas do periódico (Correio do Povo, Maio de 1968, nº 180: 02; $\mathrm{n}^{\circ}$ 184: 01; $\mathrm{n}^{\circ}$ 184: 01).

Contudo, uma interessante notícia de capa apresenta a força e a pujança do movimento estudantil em Paris: "Mais terrível do que os Vietcongs, mais forte do que o poder negro, um novo fantasma que se ergue para afrontar as autoridades, para lutar e bater a polícia e para espantar as gentes com a sua violência: o poder estudantil" (Correio do Povo, Maio de 1968, $\mathrm{n}^{\mathrm{o}}$ 184: 01.) A reportagem tem um olhar negativo sobre o movimento, caracterizando-o como altamente desafiador. Frente à necessidade de um estudo mais aprofundado, que não cabe aqui, podemos, brevemente, entender que o jornal, de alguma forma, estava tentando legitimar os atos de violência policial ${ }^{7}$ contra a subversão representada pelos movimentos estudantis brasileiros, já caracterizados como ilegais pelo governo militar do Brasil, e agora apontados como um movimento de alto grau de violência, ou seja, "justificando" intervenções militares. Assim, considerados poderosos e em maior número, os estudantes são reconhecidos, pelo jornal, como ameaça ao regime e à ordem estabelecida.

Outra reportagem que mostra, sob a ótica do Correio do Povo, a postura dos estudantes franceses frente às manifestações da França, traz o título "Sorbonne torna-se foco de idéias revolucionárias":

Centro da cultura francesa, desde o século XVIII, a Universidade parisiense de Sorbonne é, desde a segunda-feira passada, o foco das idéias mais revolucionárias que já tenham agitado a França, desde o pós-guerra. As aulas e anfiteatros da augusta instituição são, dia e noite, centro permanente

\footnotetext{
$7 \quad$ No dia 28 de março desse mesmo ano, a morte do estudante Edison Luís, no Rio de Janeiro, marca a violência policial contra os movimentos estudantis. Esse episódio frisa também a indignação popular contra esse assassinato e as repressões. Isso se evidencia no momento do enterro do rapaz, que é acompanhado por centenas de pessoas comovidas.
} 
de agitação da estudantada que sai dos caminhos tradicionais com a ambição de renovar totalmente não só os métodos de ensino, mas também os próprios fundamentos da sociedade francesa (Correio do Povo. Maio de 1968, $n^{\circ}$ 187: 03).

No livro Paris: Maio de 1968, encontra-se uma afirmação sobre o desejo dos manifestantes em suas reivindicações, e possíveis "respostas" do governo:

O remédio para eles é a adaptação: uma reforma modernizante que arrancasse as teias de aranha, aumentasse o quadro de professores, construísse melhores auditórios, aumentasse o orçamento para a educação, quem sabe um costume mais liberal no campus e, por fim, um emprego assegurado (SOLIDARITY, 2003: 17).

No jornal Correio do Povo do dia 15, pela primeira vez no mês, noticia-se, da mesma forma, a vontade expressa pelos estudantes parisienses: "As reformas incluem um sistema democrático de ingresso na universidade, a abolição da seleção, a aplicação de um ensino dialogado em vez de cursos tradicionais e maior possibilidades de emprego ao deixarem as universidades" (Correio do Povo, Maio de 1968, nº 185: 01). Explica-se, assim, o desejo dos estudantes, sob uma ótica menos "parcial", uma vez que os estudantes não são colocados como uma força bruta, nem o movimento é visto como apenas "violento".

Durante o mês, ainda encontramos matérias que legitimam essa idéia de renovação da educação pedida pelos estudantes: "A juventude está obrigando adultos a reformar o mundo" é o título, e a matéria afirma: "A educação na Europa hoje é um processo que não corresponde mais às necessidades do mundo moderno" (Correio do Povo, Maio de 1968, n 189: 07). Novamente percebe-se uma conotação positiva do jornal ao se referir às movimentações, mostrando que essa reforma na educação é necessária para acompanhar o desenvolvimento social e a modernização.

Outro fato que desperta o interesse ao folhearmos o periódico são as referências ao estado em que se encontra Paris. A imagem quase idealizada que se tinha da cidade luz sofre grande impacto pela situação em que a cidade se encontra devido às greves. Na reportagem do dia 23 de maio noticia-se: "Fecham os grandes estabelecimentos de Paris: filas para comprar comida" (Correio do Povo, Maio de 1968, $\mathrm{n}^{\circ}$ 193: 01). O repórter apresenta um quadro de 
Paris onde a cidade está suja, parada em seus serviços mais básicos, incluindo os meios de comunicação. Essa situação alerta os franceses e lhes causa pânico. No sentido de noticiar a "anarquia" que os estudantes causaram à linda cidade de Paris, lemos a seguinte reportagem: "Os acontecimentos que transformaram a vida parisiense":

Em quase uma semana, a falta de correio, transportes, incluindo taxis, lixeiros e o fechamento da maioria dos supermercados e dos bancos transformaram completamente a vida na capital [...]. Os acontecimentos são a revolta estudantil, as greves iniciadas por jovens não sindicalizados e em seguida organizadas pela CGT, e, antes de tudo, a desordem provocada na capital e em todo país pela ausência de quase todos os serviços públicos (Correio do Povo, Maio de 1968, $n^{\circ}$ 194: 02).

Isso marca também a idéia de caos e subversão dos manifestantes. Ao longo do mês, muitas matérias voltam a realçar o caráter negativo das manifestações, a partir do discurso de destruição e desordem da cidade. Evocando o passado e a tradição revolucionária do povo parisiense, encontra-se a seguinte referência: “[...] agitações que transformaram as paisagens de Paris em quadros semelhantes aos aqui pintados em vermelho durante a Revolução Francesa e a Comuna" (Correio do Povo, Maio de 1968, no 199: 01). Faz-se, aí, alusão às sangrentas batalhas ocorridas em 1789 por conta da revolução social e política contra os abusos do Antigo Regime. As analogias traçadas no jornal entre os então atuais acontecimentos parisienses e os da Revolução Francesa surgem em grande número durante o mês de maio.

Abaixo segue mais uma citação em que se mostra negativamente o panorama do estado da cidade. Contudo, podemos observar na última frase uma referência às contestações contra a sociedade de consumo e ao capitalismo, constante crítica nos discursos dos manifestantes:

[...] reinava esta manhã uma desordem completa. Árvores derrubadas, automóveis incendiados às dezenas, e lixo inundando as calçadas. Paris, sob um céu de chumbo, parece um quadro surrealista. Na Praça da Bolsa de Valores, as janelas estão quebradas e as portas forçadas. Na noite de ontem os manifestantes tentaram pôr fogo a todo o edificio aos gritos "Abaixo com ele, é o templo do capitalismo" (Correio do Povo. Maio de 1968, $n^{\circ}$ 196: 01). 
Mostra-se assim, o desagrado dos manifestantes contra o mundo regido pelo sistema capitalista, que dita o modo de vida consumista da população. As questões econômicas, de forma geral, tomam bastante espaço nas reportagens durante esse período, uma vez que não acarretam prejuízos somente na França, mas respingam em outras regiões:

O Franco começa a cair de valor. O dólar de segunda-feira para hoje não cessou de subir de cotação. Os bancos em sua absoluta maioria estão fechados. E a greve é tão assustadora que a própria Casa da Moeda, subordinada ao Banco da França, fechou suas portas. Fato com este não encontra precedente na História francesa. Até mesmo durante a revolta do Comuna, em 1871, o banco da França foi respeitado (Correio do Povo, Maio de 1968, $n^{\circ}$ 194: 13).

Torna-se relevante a identificação, em reportagens do Correio do Povo, das repercussões das manifestações sobre a crise política e econômica nacional e internacional. Em várias matérias encontramos que essa crise prejudica as relações internacionais e principalmente a economia francesa, conforme pode-se notar na notícia a seguir:

Os efeitos das greves francesas afetaram, hoje, outras nações européias, fazendo surgir os temores de graves repercussões comerciais e outros problemas econômicos se o movimento se prolongar. $O$ comércio entre a França e seus vizinhos diminuiu quando os navios, trens e caminhões carregados de mercadorias cessaram de trafegar (Correio do Povo, Maio de 1968, $n^{\circ}$ 194: 01).

Observa-se que as manifestações, que começaram na Universidade, expandiram-se para diversos setores da sociedade e acabaram por cobrir diversas regiões. Tornaram-se uma contestação política que afetou o país em todos seus âmbitos, mas principalmente, causou impacto na economia e, por consequiência, expandiu-se, rompendo as fronteiras da França e afetando outros países. O jornal apresenta esses fatos visando mostrar malefícios da greve para o país, pelos temores que causa e por sua característica "assustadora".

A capa do periódico de domingo, dia 12 de maio, traz a seguinte reportagem: "Gen. De Gaulle considera crise nacional a agitação estudantil”, apontando que essa seria a maior crise francesa que a V República já assistira. A matéria ainda se refere à noite anterior como a mais sangrenta dos últimos tempos. Essa notícia do Correio do Povo, que traz tal afirmação do 
Presidente De Gaulle, também pode ser reflexo dos acontecimentos ocorridos no dia 10 de maio, conforme aparece no texto do grupo inglês Solidarity:

Na sexta-feira, dia 10, estudantes e professores decidiram ocupar em massa o Quartier Latin. Eles achavam que tinham mais direito de estarem lá do que a polícia, visto que quartéis já haviam sido construídos para eles em outros lugares. A coesão e a clareza do objetivo dos manifestantes apavorou os poderes estabelecidos. Não se poderia permitir que o poder dormisse com essa plebe que tinha tido até mesmo a audácia de levantar barricadas (SOLIDARITY, 2003: 13-14).

Até então, evidencia-se, portanto, um discurso de duas vertentes no jornal, ora apontando os estudantes como causadores do caos e da desordem, que destroem a cidade e têm uma fúria violenta, e ora mostrando o lado positivo de suas reivindicações, por exemplo, pela coerência dos argumentos em prol da modernização do ensino e das instituições educacionais. Outro ponto relevante está em ressaltar a importância da classe operária para esse momento, conforme explicado no trecho a seguir do Solidarity:

Havia uma profunda consciência de que o problema não poderia ser resolvido no Quartier Latin, que o isolamento da revolta em um "gueto" estudantil (mesmo que em um "gueto" autônomo) significaria a derrota. Eles compreenderam que a salvação do movimento reside na sua extensão a outros setores populares (SOLIDARITY, 2003: 19-20).

A reportagem do dia 18 de maio, do jornal gaúcho, consolida a ideia de que a união entre trabalhadores e estudantes era, em suma, necessária para que as movimentações tivessem o impacto desejado. Na matéria “Onda grevista na França assume caráter nitidamente político", lemos:

Milhares de trabalhadores abandonaram os locais de trabalho e alguns ocuparam as fábricas. De uma fábrica a outra os motivos das greves variavam, mas dos 95 departamentos da França muito poucos não haviam sido afetados. As reclamações incluem aumentos de salários, redução das horas de trabalho e redução do tempo para aposentadoria.

Quase dois mil estudantes universitários marcharam hoje pelas ruas de Paris para dar demonstração de seu apoio aos trabalhadores da Renault (Correio do Povo, Maio de 1968, $n^{\circ}$ 188: 01).

Assim, as manifestações se alastraram pelos outros setores da sociedade, bem como a ocorrência de apoio recíproco entre eles. É importante chamar a atenção para o fato de que se 
esse movimento tivesse se limitado aos âmbitos estudantis, as repercussões teriam sido outras, uma vez que, iniciado nas universidades e, grosso modo, reivindicando a modernização da própria Universidade, transformou-se em uma contestação política do regime do General De Gaulle com a adesão de outros setores.

O que também ocorre é a constatação dos possíveis resultados desse período por meio da política do General. Lemos matérias do Correio do Povo que afirmam ser a figura de De Gaulle a resposta para a revolução:

Os debates da Assembléia Nacional acabaram de demonstrar que os partidos políticos são incapazes de encarapitar-se na crista da onda de agitação que sacode a França e deixam assim as portas abertas ao presidente Charles De Gaulle para se tornar o verdadeiro chefe da revolução cultural "à francesa" (Correio do Povo, Maio de 1968, $n^{\circ}$ 193: 02).

Cabe aqui apontar, de forma breve, o sentido de amplitude das manifestações do mês de maio de 1968, que é registrado no Correio do Povo, onde, ao longo do mês, encontram-se manchetes como: "Acentua-se o conflito sindical no Chile"; "Rebelião estudantil também na Alemanha"; "Polícia está em alerta face à agitação estudantil"; "Revolta dos estudantes 'maoteístas' na Suécia termina em ridículo”; “A juventude da China vermelha reluta em voltar às escolas"; "Dias de distúrbios raciais em Lousville"; "Estudantes Belgas ocupam universidade de Bruxelas"; "Espanha anuncia reforma no sistema educacional", entre outras, que vão surgindo no decorrer do mês e que apontam para um mundo em alerta, em protesto (Correio do Povo, Maio de 1968, $\mathrm{n}^{\circ}$ 179: 02; $\mathrm{n}^{\circ}$ 197: 02; $\mathrm{n}^{\circ}$ 179: 02; $\mathrm{n}^{\circ}$ 179:. 02; $\mathrm{n}^{\circ}$ 198: 03; $\mathrm{n}^{\circ}$ 200: 02; nº 193: 01; nº 195: 02). No Brasil também ocorrem manifestações, muito embora não pudessem ser noticiadas devido à censura. Pouco se encontra nas páginas do jornal.

No Brasil, as reivindicações expressas em movimentos estudantis não eram muito diferentes daquelas dos franceses, conforme visto anteriormente. No entanto, por motivos de censura, não se encontram relevantes reportagens nos jornais sobre a crise estudantil brasileira. A propósito, Gertz se refere à situação brasileira dos anos de 66 a 68:

Ao longo daqueles anos, diversas mobilizações foram realizadas em torno de questões mais amplas, como a aumento de vagas nas universidades públicas; a questão dos alunos excedentes (aprovados no vestibular, mas 
sem vaga nas universidades); as verbas para a educação, a reforma universitária e os acordos MEC-USAID; a solidariedade a estudantes vítimas de repressão em outras partes do Brasil e o protesto pela morte do estudante Edson Luís, no Rio de Janeiro etc. (GERTZ, 2007: 94).

As notícias que se tem sobre os acontecimentos nacionais são pouquíssimas se comparadas aos da França. No país, as matérias veiculadas pelo Correio do Povo que mais aparecem referem-se à crise estudantil de Curitiba, conforme constatamos com a seguinte reportagem: "Choque entre policiais e estudantes em Curitiba" (Correio do Povo, Maio de 1968, $\mathrm{n}^{\mathrm{o}}$ 185: 15). Essa reportagem noticia o protesto dos estudantes contra as novas taxas cobradas pelo Instituto Politécnico, quando foram atacados por policiais a cavalo que tentaram dissolver a manifestação. O resultado foi 10 feridos e 1 em estado grave, além da prisão de 60 estudantes, que acabaram soltos mais tarde devido a uma nova manifestação em frente ao presídio. Além disso, é interessante atentar para o modo como essas reportagens são colocadas no jornal. As matérias aparecem como pequenas notas, dentro do jornal, nunca matérias de capas.

\section{Considerações Finais}

Conforme o que foi visto, podemos afirmar que as notícias sobre os acontecimentos de 1968 na França -crise e conferência de paz- tiveram grandes repercussões nas páginas do Correio do Povo. Contudo, no que tange às manifestações, ou qualquer tipo de ocorrência no Brasil, o jornal limita-se a pequenas notas, devido à censura. Percebemos, nessa imposição restritiva aos meios de comunicação no Brasil, uma tentativa de mostrar o caos na França e, em contraponto, de buscarem passar uma imagem de paz interna do país, onde a população aceita "docilmente" o regime autoritário instalado desde 1964. Ainda podemos citar que a partir do decreto do AI-5, no final do ano de 1968, e com um rigor mais extremo, os meios de comunicação ficam proibidos de noticiar qualquer manifestação, seja na França seja no Brasil.

Sobre o posicionamento do jornal Correio do Povo, percebido por meio das notícias sobre os acontecimentos do mês de maio em Paris, nota-se uma forte oscilação no seu discurso. Em um momento mostra estudantes violentos, inclusive "mais violentos do que os 
vietcongs", fazendo alusão à Guerra do Vietnã e também anárquicos, no sentido de destruição da cidade. Em outro momento é representada a coerência das reivindicações, que são apoiadas, uma vez que lemos em suas páginas “A educação na Europa hoje é um processo que não corresponde mais às necessidades do mundo moderno". Além dessa, outras matérias fazem frequente alusão as questões que "necessitam de uma reforma modernizante".

Assim, observa-se a ambiguidade do discurso, que mostra por um lado a os acontecimentos sob uma ótica negativa - a qual se pode entender como uma mostra de apoio à repressão militar, já que essa deve fazer a manutenção da "ordem", vendo a força estudantil como uma ameaça. E, por outro lado, encontram-se matérias que destacam aspectos "positivos" das mobilizações, concordando com a urgência das modificações que o povo, nas ruas de Paris, exigia, por meio de um discurso solidário ao processo de modernização, pelo menos no que tange à educação.

Percebe-se que o jornal Correio do Povo noticiou o intenso mês de maio de 1968 em Paris de forma a registrar questões políticas e sociais que tumultuaram a França em um momento de grande importância nas relações internacionais, já que a cidade luz oferecia-se para sediar o acordo de paz entre o Vietnã do Norte e os Estados Unidos. As repercussões desse tão esperado acontecimento abrangeram boa parte do mundo e as notícias sobre as mobilizações contrárias ao regime também alarmaram o mundo devido ao pano de fundo francês: protestos, greves e paralisações quase gerais. Noticiou-se que Paris ficou desprovida dos meios mais básicos necessários para o funcionamento da cidade: transporte, alimentação, higiene etc. Tudo isso, sem contar o resultado das demolições urbanas, que refletiam a intensidade e a gravidade dos acontecimentos.

Face ao legado que essas manifestações do ano de 1968 deixaram para a sua geração, pensamos que o espírito que fortificava as manifestações era de liberdade, autonomia e independência -fatores chave que motivaram as demais transformações exigidas do período. Foi, de certo, uma transgressão de valores, idéias ultrapassadas, padrões que já não serviam à juventude da época. As rupturas buscadas aconteceram de diversas formas, em atividades da 
música, da moda, da dança, de um novo estilo de comportamento e de relações, conquistadas em protestos, barricadas, violência e grito.

A revolução comportamental, o feminismo, o homossexualismo, movimentos hippies, a decadência dos valores religiosos e familiares, a liberação sexual, a flexibilização nas hierarquias (aluno-professor, pais e filhos), as questões ecológicas que passam a ser preocupações, a ideia de infância transformada, tudo isso foi reflexo do que os movimentos conseguiram naquele ano de 1968, oscilante entre o trágico e o poético.

A peculiaridade do maio de 68 ou talvez do ano de 1968, seja que nunca antes houve nada parecido nem houve outro "maio de 68" depois desse. O interessante fica por conta de ser um movimento jovem e estudantil -embora também tenha se expandido a outros setores-, que serviu não só para acelerar um reforma modernizante nas instituições de ensino superior, mas também para afirmar a juventude no mundo, marcando seu espaço e reivindicando respeito.

É também importante registrar que, na Paris de 68, o uso dos panfletos e das pichações nas paredes demonstram a irreverência dos acontecimentos. Frases de protesto ficaram gravadas, não nas paredes, mas na sociedade, eternizando assim, o desagrado dos manifestantes de uma época e de um regime antiquado demais para eles: "A publicidade te manipula"; "A arte está morta, não consuma seu cadáver"; "Não à Universidade de classe"; "Universidade democrática"; "Guy Mollet, para o museu"; "É proibido proibir"; "O poder está nas ruas”; “Abaixo o Estado policial” (SOLIDARITY, 2003).

Conclui-se, portanto, que, o ano de 1968 ganha um sentido emblemático, sendo um dos anos mais lembrados quando o assunto é protestos. Não poderia ser de outra forma, uma vez que as mudanças, diga-se radicais -“de raiz”-, ocorridas nesse ano, transformaram as estruturas sociais, culturais e comportamentais da sociedade em grande parte do mundo. A irreverência da classe estudantil, pela primeira vez, é mostrada com toda a crueza de sua própria juventude e força frente a um contexto que incentivava e aprovava o calar das vozes e buscava punir aquelas que ousavam falar.

\section{Referências}


DILlENBURG, Sérgio Roberto. Correio do Povo: história e memória. Passo Fundo: Ediupf, 1997.

GALVANI, Walter. Um século de poder: os bastidores da Caldas Júnior.Porto Alegre: Mercado Aberto, 1999.

GERTZ, René E. (org). História geral do RS - República: da revolução de 1930 à Ditadura Militar - Volume 4. Passo Fundo: Méritos, 2007.

HOBSBAWN, Eric. A era dos extremos: O breve século XX (1914 - 1991). São Paulo: Companhia das Letras, 1997.

HOLLANDA, Heloisa B. de. Cultura e participação nos anos 60. São Paulo: Editora Brasiliense, 1982.

JUDT, Tony. Pós-guerra: uma história da Europa desde 1945. Rio de Janeiro: Objetivo, 2008.

MARTINS, Ana Luiza \& LUCA, Tania Regina de (orgs.). História da imprensa no Brasil. São Paulo: Contexto, 2008.

PEREIRA, Carlos Alberto Messeder. O que é contracultura. São Paulo: Editora Brasiliense, 1985.

REIS, Daniel Aarão. 1968: O curto ano de todos os desejos. In: Ciências e Letras. Porto Alegre: Faculdade Porto-alegrense de Educação, No 22, 2000, p. 43-53.

REZENDE, Maria José. A ditadura militar no Brasil: Repressão e pretensão de legitimidade (1964-1984). Londrina: Editora UEL, 2001.

SCHILlING, Voltaire. 1968, a revolução inesperada. Caderno de História do Rio Grande do Sul. Porto Alegre: Memorial do Rio Grande do Sul, 2008.

SOLIDARITY. Maio de 1968. São Paulo: Conrad Editora do Brasil, 2003.

TRONCOSO, Alberto Del Castilho. O movimento estudantil de 1968 na cidade do México visto através da fotografia. Clio - Série Revista de Pesquisa Histórica, N. 26-1, 2008, p. 11-34.

VENTURA, Zuenir. 1968: о ano que não terminou - A aventura de uma geração. Rio de Janeiro: Nova Fronteira, 1988.

\section{Fontes documentais:}

Correio do Povo. Porto Alegre, Maio de 1968. N ${ }^{\text {os }} 176-200$. 